\title{
lodine Deficiency: An Ancient Problem in a Modern World
}

\section{INTRODUCTION}

Iodine has long been known as an essential element for humans, and for mammals in general, where it is concentrated in the thyroid gland, being a vital component of the thyroid hormone thyroxine. Deprivation of iodine results in a series of iodine deficiency disorders (IDD), the most commonly recognized of which is endemic goiter, a condition where the thyroid gland becomes enlarged in an attempt to be more efficient. Iodine deficiency during fetal development and in the first year of life can result in endemic cretinism, a disease that causes stunted growth and general development, together with brain damage. However, although these 2 diseases are easily recognizable, the more insidious problem is that iodine deficiency impairs brain development in children, even when there is no obvious physical effect; indeed, it has been suggested that iodine deficiency is the most common preventable cause of mental retardation.

Endemic goiter and cretinism, together with related IDD, have long been recognized as serious health problems, and, consequently, much work has been carried out on the etiology and geographical distribution of these diseases. Although it has been suggested that other elements and factors may be involved, it is generally agreed that the primary cause of IDD is a lack of iodine in the diet.

Endemic goiter appears to have been identified by the ancient Chinese, one Chinese medical writer from the 4th century AD noted the use of the brown seaweeds Sargassum and Laminaria (which are now known to be very iodine rich) for its treatment (1). However, there are many earlier records in ancient literature of seaweeds and burnt sea sponges being used in the treatment of endemic goiter possibly from as early as $2700 \mathrm{BC}$ (1). Iodine was discovered by the French chemist Bernard Courtois in 1811 when he accidentally added concentrated sulfuric acid to the seaweed Fucus vesiculosus, one of the seaweeds used in goiter treatment. It was soon realized that iodine was the active ingredient in the treatment, being identified as an essential element in human nutrition, consequently, thyroxine was discovered and identified in 1919.

Despite this early recognition of the role of iodine in endemic goiter and related disorders, it is apparent that IDD is still affecting large numbers of people worldwide, with some estimates suggesting that around 2 thousand million of the world's population are at risk. Before the middle of the 20th century iodine deficiency problems affected virtually every country (2). Subsequent to the addition of iodine to the diet as a prophylactic, mainly through iodized salt, IDD had more or less been eradicated from the developed world by the 1970s and were generally regarded as diseases of the poor. Although a large percentage of those currently at risk of IDD are located in the developing world, over the last 15 years or so it has reemerged in some of the more affluent countries of Western Europe, such as Austria, Belgium, Demark, Germany, and France, and is also re-emerging in other countries, e.g., Australia. Based on the data of Dunn and van der Haar (3), Figure 1 indicates the general global distribution of IDD.

\section{IODINE GEOCHEMISTRY}

A brief look at iodine geochemistry reveals that it is unique among the elements. Most elements in soil and water are derived from weathering of the lithosphere; in general, that is not the case with iodine. Most of the iodine in the pedosphere and the hydrosphere derives from the marine environment via the atmosphere. Iodine is very low in the lithosphere, $0.25 \mathrm{mg}$ $\mathrm{kg}^{-1}$ on average, with sea water being the major terrestrial reservoir of iodine, containing approximately $60 \mathrm{mg} \mathrm{L}^{-1}$.

The major feature of iodine geochemistry is its volatility. It is volatilized from the sea in 2 main forms, firstly as elemental iodine, because of the action of ultraviolet light and possibly ozone. Secondly, it is known that it volatilizes as methyl iodide, $\mathrm{CH}_{3} \mathrm{I}$, and other organic iodine species, most probably because of biological involvement. In these gaseous forms in the atmosphere, it is carried onto the terrestrial environment, where it is deposited onto soils by wet and dry precipitation. So most terrestrial iodine derives from the marine environment by way of volatilization, so that soils in coastal areas are strongly enriched in iodine compared with those from areas remote from the sea. Subsequently, iodine can be revolatilized from soils and terrestrial waters.

Iodine was the first trace element recognized as being essential for humans; why then do IDDs persist and reoccur in affluent countries? This author suggests that the reason is that there is a widespread misunderstanding about iodine geochemistry and pathways into the biosphere and, ultimately, humans. There are 2 generalizations with regard to iodine biogeochemistry, firstly, as a consequence of its derivation from the sea, it has been suggested that only areas remote from marine influence are problem areas for IDD. Although central continental and rain shadow areas of high mountain ranges are seriously affected by IDD, it is very questionable that areas close to marine influence are unaffected. The second generalization is that plants or crops provide the major dietary source of iodine; this is also very questionable.

A brief look at the data for iodine distribution in soils confirms that it is strongly enriched in coastal soils, compared with those inland (4). However, traverses of topsoil samples taken at increasing distances from the coast reveal that the strong iodine enrichment is confined to a fairly limited zone close to the coast. From traverses from the west coast of Wales, United Kingdom (5), and Morocco (6), it is apparent that strong soil-iodine enrichment is limited to about $100-120 \mathrm{~km}$ from the coast. Beyond this distance concentrations of iodine are close to the values found in central continental regions. Previously unpublished data for a traverse inland from the west coast of the Republic of Ireland, illustrated in Figure 2, also demonstrates this phenomenon.

The iodine content of soils is governed not only by its supply, generally reflecting proximity to the coast, but also by the ability of the soil to retain the added iodine. Iodine retention in soils is strongly influenced by soil type. Thus organic-rich soils are frequently enriched in iodine, with peats having some of the highest values recorded for iodine in soils. Iron-rich and clayrich soils are enriched in iodine, whereas sandy soils and waterlogged soils are generally depleted. It is also apparent that 


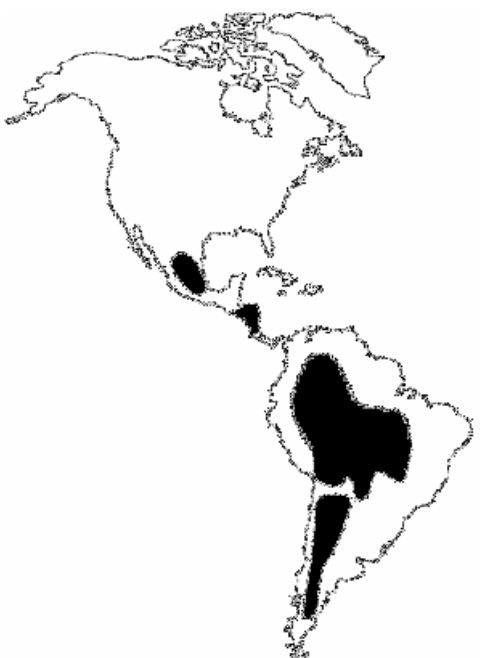

soils over limestone are generally richer in iodine compared with soils overlying other lithologies in the same regions.

\section{IODINE UPTAKE BY PLANTS}

The iodine content of soils from some areas of the United Kingdom that have historical records of IDD are listed in Table 1. It is of interest to note that many of these are relatively high in iodine. So why do we find iodine deficiency disorders in areas with relatively high soil iodine?

The major problem is that iodine is very strongly held in soil, less than $10 \%$ and generally much less than $10 \%$, is water soluble. There is no correlation of iodine in soils with plants growing on those soils, and it is generally agreed that the soilplant transfer factors for iodine are very low. Both anionic forms of iodine, iodide $\left(\mathrm{I}^{-}\right)$and iodate $\left(\mathrm{IO}_{3}^{-}\right)$are very large ions. Despite the large size of these anions, it has been shown that iodine is taken into the roots of plants with $\mathrm{I}^{-}$being more readily incorporated than $\mathrm{IO}_{3}{ }^{-}$. Even so, it has been shown that whereas iodine gets into the roots, it is not translocated into the aerial parts of the plants. However, it has been shown that plants can take in iodine through their aerial parts through the stomata in the leaves, this being thought to be a far more important source than root uptake. It is likely, therefore, that volatilization of iodine from soils is a very important pathway into plants and that if such volatilization does not occur, then the plant is deprived of its major source of iodine.

It is of interest to note that many goiter endemias have been recorded in regions underlain by limestone, such as the Peak District of Derbyshire, England, where iodine in soils is relatively enriched (Table 1). Frequently, soils in limestone areas are circum-neutral to alkaline, and under these conditions iodine is unlikely to be volatilized. Similarly, in England and Wales, some goitrous areas occur where peaty soils predominate, again these are high iodine soils (Table 1). It is likely that peaty soils retain iodine very tightly and so little is available to be volatilized.

\section{SOURCES OF DIETARY IODINE}

It is traditionally perceived that vegetables and crops are the sources of iodine for humans. However, plants are generally low in iodine, and vegetarian diets have been singled out as being iodine deficient. In general, animal produce is a better source of dietary iodine than plants. Until fairly recently, the use of iodophores, iodine-containing disinfectants, in the dairy industry resulted in dairy produce being a very major source of dietary iodine. However, iodophors are not used to the same degree currently, so that dairy produce is not as enriched in iodine. Despite this, dairy produce is still an important source of dietary iodine, because cattle feeds are supplemented with iodine.

It is also worth pointing out that grazing animals are likely to take in appreciable quantities of iodine because iodine volatilized from soils is deposited on the surfaces of vegetation rather than incorporated into the plant. Likewise, soil splashes onto leaves and soil inadvertently consumed by animals is going to be a richer source of iodine than the vegetation growing on it. This has been demonstrated in New Zealand and Tasmania, where sheep found to be ingesting soil containing only $1 \mathrm{mg}$ $\mathrm{kg}^{-1}$ of iodine did not suffer from iodine deficiency.

Seafood is generally a rich source of iodine and, in particular, seaweed. In some countries, such as Japan and Iceland, where there is a high consumption of seafood, some populations have been found to be consuming too much iodine and, as a result, have suffered iodine thyrotoxicosis. In some regions of the world, drinking water derived from groundwater is rich in iodine and can constitute a major source of dietary iodine; but, in most cases, water is a poor source of dietary iodine.

It has been suggested that burning of high iodine coals in some rural iodine-deficient areas of China has impacted populations living in these areas, resulting in a lower incidence of IDD (7).

The most important source of dietary iodine, and the major reason for the drop in IDD in the mid 1900s, is iodized salt.

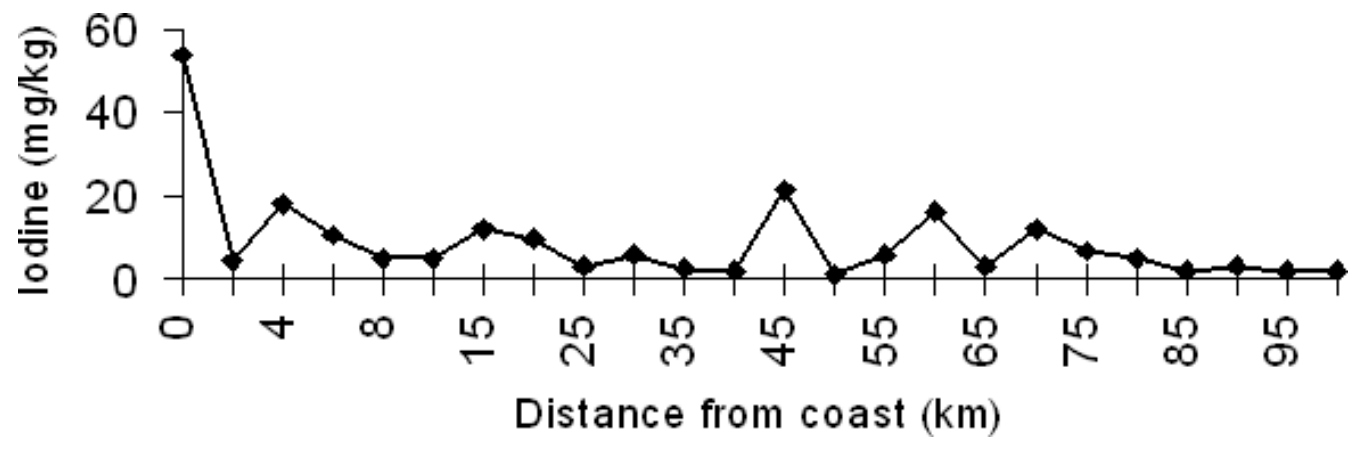

Figure 2. lodine in topsoils in a traverse inland from the west coast of Ireland. 


\begin{tabular}{|c|c|c|}
\hline Area & Range (ppm) & Mean \\
\hline Peak District, Derbyshire & $2.6-26$ & 8.2 \\
\hline North Wales & $3.4-14.5$ & 9.8 \\
\hline Dartmoor & $10-35$ & 21 \\
\hline North Oxfordshire & $4.8-11$ & 6.2 \\
\hline
\end{tabular}

However, in modern diets consumption of relatively high quantities of salt is regarded as somewhat harmful, resulting in high blood pressure. In addition, in the affluent world, there has been a general move away from preparing all meals in the home. It is now commonplace for processed foods to be purchased, and such foods contribute the major part of salt in the diet. Such foods, in general, are not prepared with iodized salt. Hence, a very important source of dietary iodine is minimal in modern diets. Added to this, another important source of dietary iodine is dairy produce, and current health fads suggest that one should not eat too much dairy produce, because it is harmful. So that there are a large numbers of people in the developed world now who drink very little milk and consume little or no dairy produce and consume little iodized salt, thereby making their diets very low in iodine. It is apparent that with modern diets in affluent countries IDD are likely to be become even more common.

\section{CONCLUSIONS}

It is perhaps worth noting that humans evolved from marine life forms and that the marine environment is enriched with iodine. Early terrestrial animals lived close to the sea, but, on moving inland, they moved from the major source of iodine. Once they got further than 100 or so kilometers from the sea, the marine source of iodine was cut off. Humans evolved in areas fairly remote from the sea, and, as a consequence, it is probable that iodine deficiency is the norm and most diets are marginal. It has been suggested that a third of the world population are at risk of IDD; the author suspects that a great deal more than that are at risk and if modern dietary trends continue an even greater upsurge of iodine deficiency disorders will occur in the affluent countries of the world.

\section{References and Notes}

1. Langer, P. 1960. History of goitre. In: Endemic Goitre. World Health Organisation, Geneva, Switzerland, pp. 9-25.

2. Kelly, F.C. and Sneddon, F.W 1960. Prevalence and distribution of endemic goitre In: Endemic Goitre. World Health Organisation, Geneva, Switzerland, pp. 27-233.

3. Dunn, J. T. and van der Haar, F 1990. A Practical Guide to the Correction of Iodine Deficiency. Technical Manual No. 3. International Council for the Control of Iodine Deficiency Disorders, Wageningen, The Netherlands, $62 \mathrm{pp}$

4. Fuge, R. 2005. Soils and iodine deficiency. In: Essentials of Medical Geology. Selinus, O, Alloway, B., Centeno, J. A., Finkelman, R. B., Fuge, R., Lindh, U. and Smedley, P. (eds). Elsevier, San Diego, CA, pp. 417-433.

5. Fuge, R. 1996. Geochemistry of iodine in relation to iodine deficiency diseases. In: Environmental Geochemistry and Health. Appleton, J.D., Fuge, R. and McCall, G.J.H. (eds). Geological Society Special Publication 113, The Geological Society, London, pp. 201-211.

6. Johnson, C. C. 2003. The Geochemistry of Iodine and Its Application to Environmental Strategies for Reducing the Risks from Iodine Deficiency Disorders (IDD). Report CR/03 Strategies for Reducing the Risks from Iodine Deficiency Disorders (IDD).

7. Finkelman, R. B. 2007. Health Impacts of Coal: Facts and Fallacies. Ambio 36, 103-106.

Ron Fuge, Institute of Geography and Earth Sciences, University of Wales, Aberystwyth, Ceredigion, SY23 3DB, UK. rrf@aber.ac.uk 